\title{
Modification of 13X Molecular Sieve by Chitosan for Adsorptive Removal of Cadmium from Simulated Wastewater
}

\author{
Yan Shi ${ }^{1}$, Ken Sun ${ }^{1}$, Lixin Huo ${ }^{1}$, Xiuxiu $\mathrm{Li}^{2}{ }^{2}$ Xuebin $\mathrm{Qi}^{3, *}$ and Zhaohui $\mathrm{Li}^{4, *}$ \\ 1 School of Environmental and Municipal Engineering, North China University of Water Resources and \\ Electric Power, Zhengzhou 450045, China; shiyan@ncwu.edu.cn (Y.S.); sunken@ncwu.edu.cn (K.S.); \\ 18748975624@163.com (L.H.) \\ 2 Henan Province key Laboratory of Water-Saving Agriculture, North China University of Water Resources \\ and Electric Power, Zhengzhou 450045, China; lixiuxiu@163.com \\ 3 Farmland Irrigation Research Institute, CAAS, Xinxiang 453002, China \\ 4 Geosciences Department, University of Wisconsin-Parkside, Kenosha, WI 53144, USA \\ * Correspondence: qxb6301@yahoo.com.cn (X.Q.); li@uwp.edu (Z.L.)
}

Received: 9 August 2017; Accepted: 13 September 2017; Published: 19 September 2017

\begin{abstract}
Chitosan was used to modify a $13 \mathrm{X}$ molecular sieve to improve its cadmium removal capability. After being modified with $2 \%$ chitosan-acetate for $2 \mathrm{~h}$ at $30^{\circ} \mathrm{C}$, significant uptake of $\mathrm{Cd}^{2+}$ could be achieved. The uptake of $\mathrm{Cd}^{2+}$ on the modified 13X molecular sieve followed the Langmuir isotherms with a capacity of $1 \mathrm{mg} / \mathrm{g}$. The kinetics of $\mathrm{Cd}^{2+}$ removal by modified $13 \mathrm{X}$ molecular sieve followed a pseudo second-order reaction, suggesting chemisorption or surface complexation. The $\mathrm{Cd}^{2+}$ removal with a sorbent dose of $2 \mathrm{~g} / \mathrm{L}$ from an initial concentration of $100 \mu \mathrm{g} / \mathrm{L}$ reached more than $95 \%$ in $90 \mathrm{~min}$. The equilibrium $\mathrm{Cd}^{2+}$ concentration was $<5 \mu \mathrm{g} / \mathrm{L}$, which meets the requirements of "Standards for Irrigation Water Quality" (GB5084-2005) (10 $\mu \mathrm{g} / \mathrm{L})$ and MCL and MCLG for groundwater and drinking water $(5 \mu \mathrm{g} / \mathrm{L})$ set by United States Environmental Protection Agency.
\end{abstract}

Keywords: cadmium; chitosan; modification; $13 \mathrm{X}$ molecular sieve; removal

\section{Introduction}

Cadmium $(\mathrm{Cd})$ is a major water pollutant. With a high toxicity, $\mathrm{Cd}$ can cause chronic intoxication with an incubation period from 10 to 30 years. The half-life of $\mathrm{Cd}$ in the human body also varies between 10 and 30 years. People can develop gastroenteropathy or even hepatopathy, lung cancer, kidney disease, with continuing intake of food or water contaminated with Cd [1-4]. Currently, the USEPA has set both the maximum contamination level (MCL) and maximum contamination level goal (MCLG) at $5 \mu \mathrm{g} / \mathrm{L}$ [5]. Although its concentration in unpolluted natural waters was usually below $1 \mu \mathrm{g} / \mathrm{L}$ [6], a maximum value of $100 \mu \mathrm{g} / \mathrm{L}$ was reported in Rio Rimao in Peru [7]. In addition, the presence of Cd as an impurity in zinc in galvanized pipes may have potential for drinking water contamination. A mean concentration of 1-26 $\mu \mathrm{g} / \mathrm{L}$ was found in samples of potable water in Saudi Arabia [8].

$\mathrm{Cd}$ cannot be microbiologically degraded in the natural environment, and can only be dispersed, enriched, or converted between its various forms [9]. The migration process of $\mathrm{Cd}$ in water is mainly dependent on precipitation, complexation, and adsorption. Although natural zeolite has high cation exchange capacities (CEC), its internal channels of different sizes make the uptake of heavy metal ions more kinetically controlled $[10,11]$. In addition, natural zeolite may have other impurities that can make water purification less effective. Compared with natural zeolite, synthetic zeolite has simpler phases and compositions, with less impurity, which avoids secondary pollution. Its internal pore channels and holes would be of uniform size, which can be regulated by adjusting the synthesis 
conditions, as well as larger internal and external surface area, good physical and chemical stability, exchange, adsorption, and catalysis capacities make it a good candidate for water treatment [12,13]. In particular, the synthetic 13X zeolite molecular sieve (MS) has a cubic crystal system with 3D pore channels, which can provide a faster intracrystalline diffusion for adsorption and catalysis $[14,15]$. However, its uptake of cationic heavy metals may be low.

Containing a large number of amino and hydroxyl groups, chitosan has high hydrophilicity and can absorb heavy metals in wastewater [16-18]. Chitosan-modified natural zeolite can achieve good removal performance of heavy metals (mostly $\mathrm{Cu}(\mathrm{II}), \mathrm{Fe}(\mathrm{III}), \mathrm{Mn}(\mathrm{II}), \mathrm{Zn}(\mathrm{II})$ ) from wastewater with high concentrations [19-26]. However, little research has been conducted into the treatment of wastewater with low $\mathrm{Cd}^{2+}$ concentrations using chitosan-modified 13X molecular sieves (CMS). Therefore, in this study, conditions were optimized for the modification of MS by chitosan, and the CMS was tested for the removal of low concentrations of $\mathrm{Cd}^{2+}$ from simulated wastewater, so that the $\mathrm{Cd}^{2+}$ concentration would meet the discharge standards of $10 \mu \mathrm{g} / \mathrm{L}$ set by the Standards for Irrigation Water Quality (GB5084-2005), and $5 \mu \mathrm{g} / \mathrm{L}$ of MCL and MCLG set by USEPA. The results also provide technical support for safe use of unconventional water in agriculture.

\section{Materials and Methods}

\subsection{Materials}

The 13X molecular sieve was off-white in color with a grain size of 2 to $3 \mathrm{~mm}$, and was purchased from Zhengyuan Haoye Chemical Technology Co. (Tianjing, China). Chitosan (food grade with 95\% deacetylation) was purchased from Zhengzhou Mingrui Food Ingredients, Co., Ltd. (Zhengzhou, China) Nitric acid, hydrochloric acid, sodium hydroxide, glacial acetic acid, and $\mathrm{Cd}^{2+}$ stock solution $(1.000 \mathrm{~g} / \mathrm{L})$ were all of reagent grade or analytical pure and were purchased from Zhiyuan Chemical Technology Co. (Tianjing, China).

\subsection{Preparation of $C M S$}

The MS was washed with tap water several times to remove the impurities, and then washed with deionized water 2-3 times before being dried at $105^{\circ} \mathrm{C}$ for modification. The MS was added to chitosan solutions of different concentrations ( $0.5-3.0 \%)$ under acidic conditions to increase the solubility of chitosan $[16,18]$. The mixture was shaken under a constant temperature of $30^{\circ} \mathrm{C}$ at $120 \mathrm{rpm}$ for $30,60,90$, 120,150 , and $180 \mathrm{~min}$, before being washed with deionized water to neutral condition and dried at $55^{\circ} \mathrm{C}$.

\section{3. $\mathrm{Cd}^{2+}$ Adsorption Experiments}

$0.1 \mathrm{~g}$ of CMS was added into a conical flask, and then $100 \mathrm{~mL}$ of simulated wastewater containing $25,50,75,100,150,200$, and $250 \mu \mathrm{g} / \mathrm{L}$ of $\mathrm{Cd}^{2+}$ were added. The mixtures were stirred under constant temperature of $25^{\circ} \mathrm{C}$ at $130 \mathrm{rpm}$ for varying amounts of time. The supernatant was removed and the $\mathrm{Cd}^{2+}$ concentration was determined by a flame atomic adsorption spectrometry (FAAS) (WFX-210, Beifen-Ruili Analytical Instrument Co., Beijing, China). The amount of $\mathrm{Cd}^{2+}$ removed was calculated by the difference between the initial and equilibrium $\mathrm{Cd}^{2+}$ concentrations divided by the solid mass and multiplied by the liquid volume. The $\mathrm{Cd}^{2+}$ removal was calculated by the difference between the initial and equilibrium $\mathrm{Cd}^{2+}$ concentrations multiplied by 100. All experiments were done in triplicate, and the average and standard deviations are plotted in the figures.

\subsection{Material Characterization}

The material characterization was conducted using JSM-7500F scanning electron microscope (JEOL, Tokyo, Japan) equipped with energy dispersion spectrum (EDS) system. The BET analysis was performed at $120^{\circ} \mathrm{C}$ after $60 \mathrm{~min}$ degassing with a $\mathrm{N}_{2}$ temperature of $77 \mathrm{~K}$. The XRD was performed on a D8 Focus diffractometer from Bruker (Karlsruhe, Germany). Samples were run from 5 to $80^{\circ}(2 \theta)$ with a scanning speed of $2^{\circ} / \mathrm{min}$. The thermogravimetric analysis (TGA) was conducted using STA 
PT1600 Simultaneous Thermal Analysis manufactured by Linseis (Munich, Germany). The initial mass used was $10 \mathrm{mg}$, and the heating rate was $10^{\circ} \mathrm{C} / \mathrm{min}$. The FTIR spectra were recorded on an IRAffinity FTIR spectrophotometer made by Shimadzu (Tokyo, Japan). Standard KBr pressing method was used for sample preparation and the scan was recorded from 500 to $4000 \mathrm{~cm}^{-1}$.

\section{Results and Discussion}

\subsection{Effects of Different Modification Conditions on $\mathrm{Cd}^{2+}$ Removal}

The initial chitosan concentrations used for the preparation of CMS was assess first. When the chitosan concentration increased from $0.5 \%$ to $2 \%$, the percentage of $\mathrm{Cd}^{2+}$ removal from simulated wastewater showed an increasing tendency. Beyond $2 \%$, further increase of chitosan content did not affect $\mathrm{Cd}^{2+}$ removal much. At $2 \%$ chitosan modification, the $\mathrm{Cd}^{2+}$ removal by CMS reached up to $90 \%$ (Figure 1).

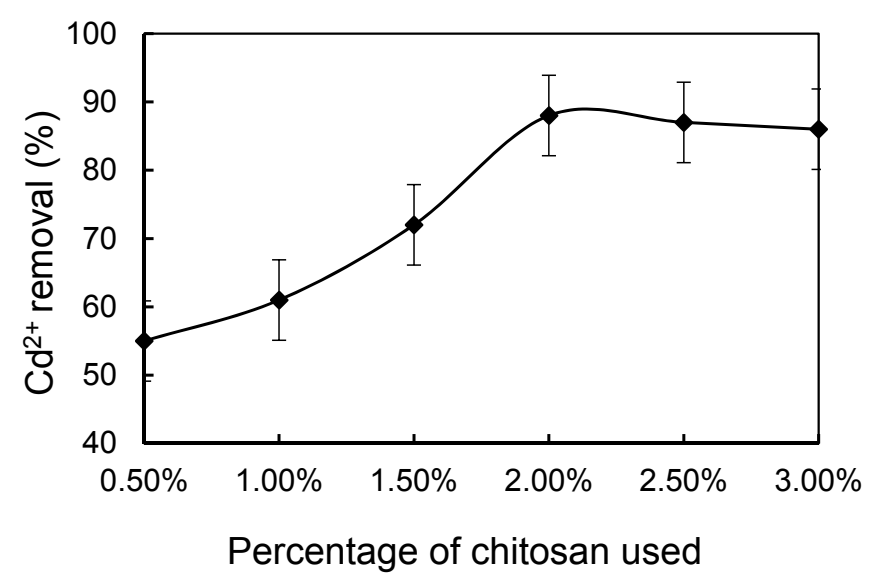

Figure 1. Effect of initial chitosan usage on $\mathrm{Cd}^{2+}$ removal.

Chitosan belongs to the natural macromolecule amylose, which has similar properties to chitin and cellulose. When the chitosan concentration was over $2 \%$, a gel-like condition was formed, which limited the contact between chitosan molecules and MS. Therefore, the optimal concentration of chitosan was set at $2 \%$ for the fabrication of CMS.

The effect of time of chitosan modification on $\mathrm{Cd}^{2+}$ removal was assessed next, with $\mathrm{Cd}^{2+}$ removal peaking at $120 \mathrm{~min}$ (Figure 2). Thus, for the detailed $\mathrm{Cd}^{2+}$ removal experiment, the MS was modified by $2 \%$ chitosan for $120 \mathrm{~min}$.

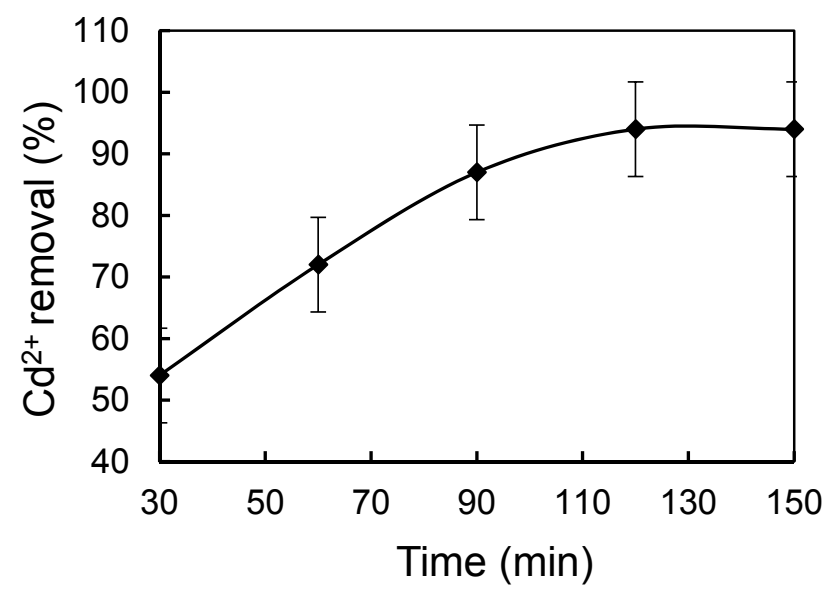

Figure 2. Effect of time of chitosan modification on $\mathrm{Cd}^{2+}$ removal. 


\subsection{Material Characterization of MS and CMS}

The MS showed granular particles with smooth surfaces and a particle size of 2-3 $\mu \mathrm{m}$ (Figure 3a). A similar texture was found for the CMS. The SEM images confirmed that the modification did not change the morphology or the internal structure much (Figure 3b). The EDS analyses showed that the MS was mainly composed of $\mathrm{O}, \mathrm{Na}, \mathrm{Al}$, and $\mathrm{Si}$ elements (Figure 3c). The CMS showed an increase in $\mathrm{C}$ peak height, as well as the peak at $2.1 \mathrm{keV}$, attributed to the $\mathrm{N}$ element, confirming the uptake of chitosan on the MS (Figure 3d). Although the substitution of $\mathrm{Al}$ for $\mathrm{Si}$ in tetrahedron resulted in negative charges, the amount of substitution in the MS is relatively small. The BET surface area was 636 and $637 \mathrm{~m}^{2} / \mathrm{g}$, the average pore size was 2.5 and $2.4 \mathrm{~nm}$, and the pore volume was 0.35 and $0.35 \mathrm{~cm}^{3} / \mathrm{g}$ for MS and CMS, respectively. The MS results agreed well with a previous study [14]. The uptake of chitosan on MS resulted in a great increase in negative charges. Therefore, its uptake of $\mathrm{Cd}^{2+}$ was enhanced.
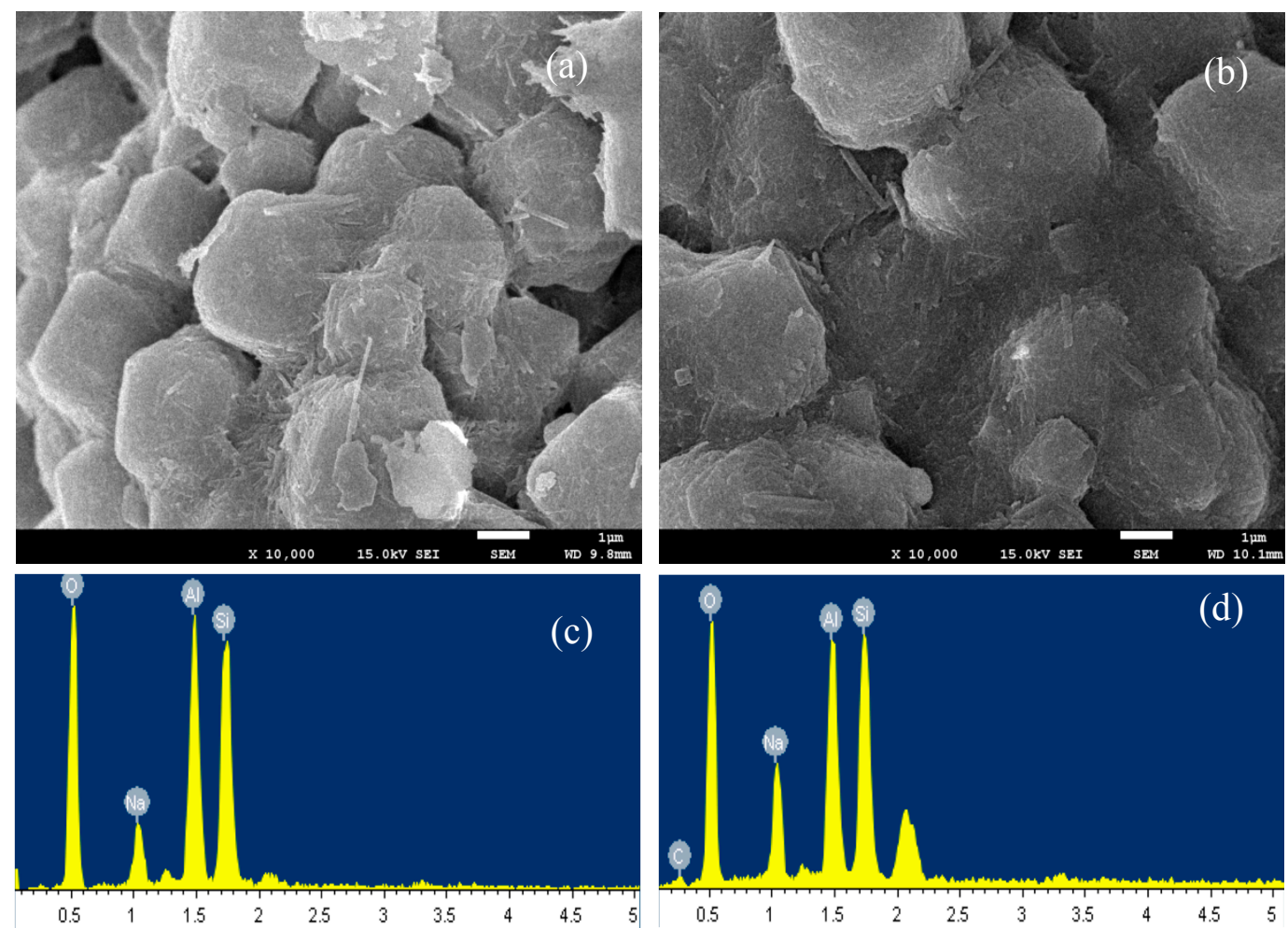

Figure 3. SEM images of MS (a) and CMS (b) and EDS images of MS (c) and CMS (d).

The X-ray diffraction (XRD) analyses before and after chitosan modification showed no change in material phases or structure (Figure 4), suggesting that the uptake of chitosan was on the external surfaces. The TGA showed slight different in mass loss (Figure 5). After chitosan modification, there was $2 \%$ more mass loss, which could be attributed to mass loss by chitosan. The FTIR analyses showed vibrations at 2850 and $2920 \mathrm{~cm}^{-1}$, attributed to the vibration of chitosan after modification (Figure 6). All these results showed successful modification of MS by chitosan. 


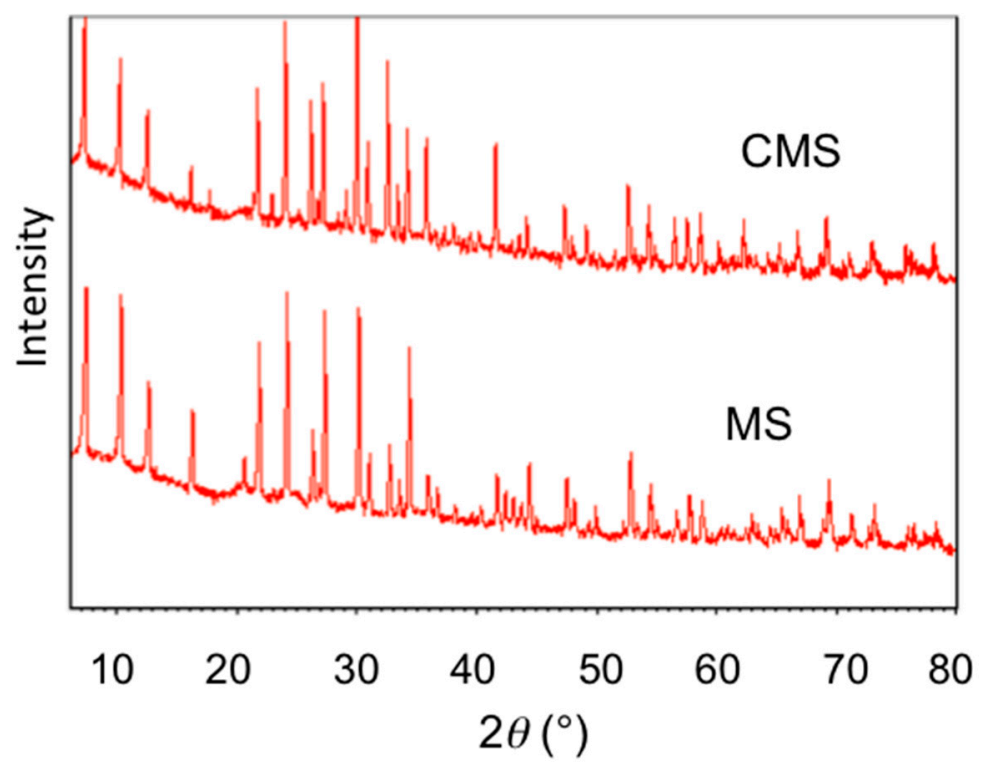

Figure 4. XRD patterns of MS and CMS.

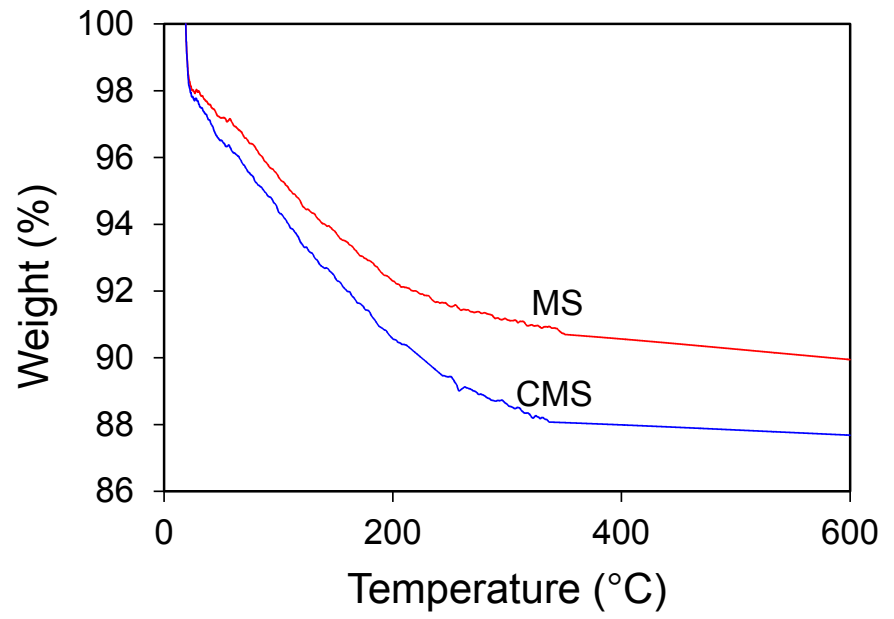

Figure 5. Thermogravimetric analysis of MS and CMS.

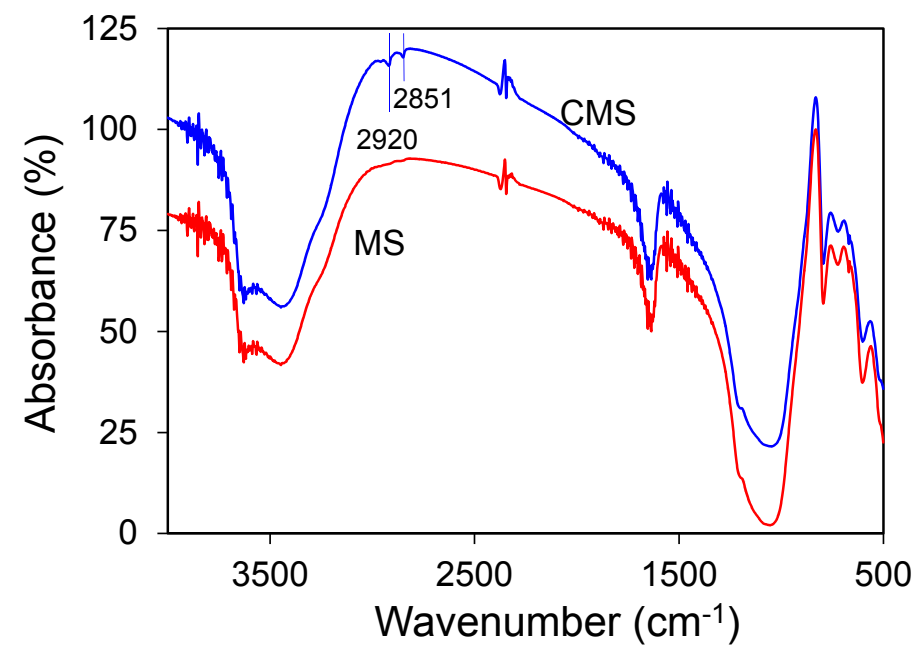

Figure 6. FTIR analysis of MS and CMS. 


\subsection{Effect of Different Physicochemical Conditions on $\mathrm{Cd}^{2+}$ Removal by CMS}

With an initial $\mathrm{Cd}^{2+}$ concentration of $100 \mu \mathrm{g} / \mathrm{L}$, the $\mathrm{Cd}^{2+}$ uptake and removal varied with equilibrium solution $\mathrm{pH}$ (Figure 7). When the solution $\mathrm{pH}$ increased from 4 to 7 , the $\mathrm{Cd}^{2+}$ removal increases quickly from $33.7 \%$ to $97.4 \%$. This is mainly because of the fact that, in acid solutions, a high concentration of $\mathrm{H}$ ions is in competitive adsorption against $\mathrm{Cd}^{2+}$ ions, which impacts the adsorbing effect of the adsorbent. However, with further increase of solution $\mathrm{pH}$ beyond 7, the change in $\mathrm{Cd}^{2+}$ uptake did not change much (Figure 7). Therefore, the optimal $\mathrm{pH}$ value for maximal $\mathrm{Cd}^{2+}$ removal was determined to be 7 .

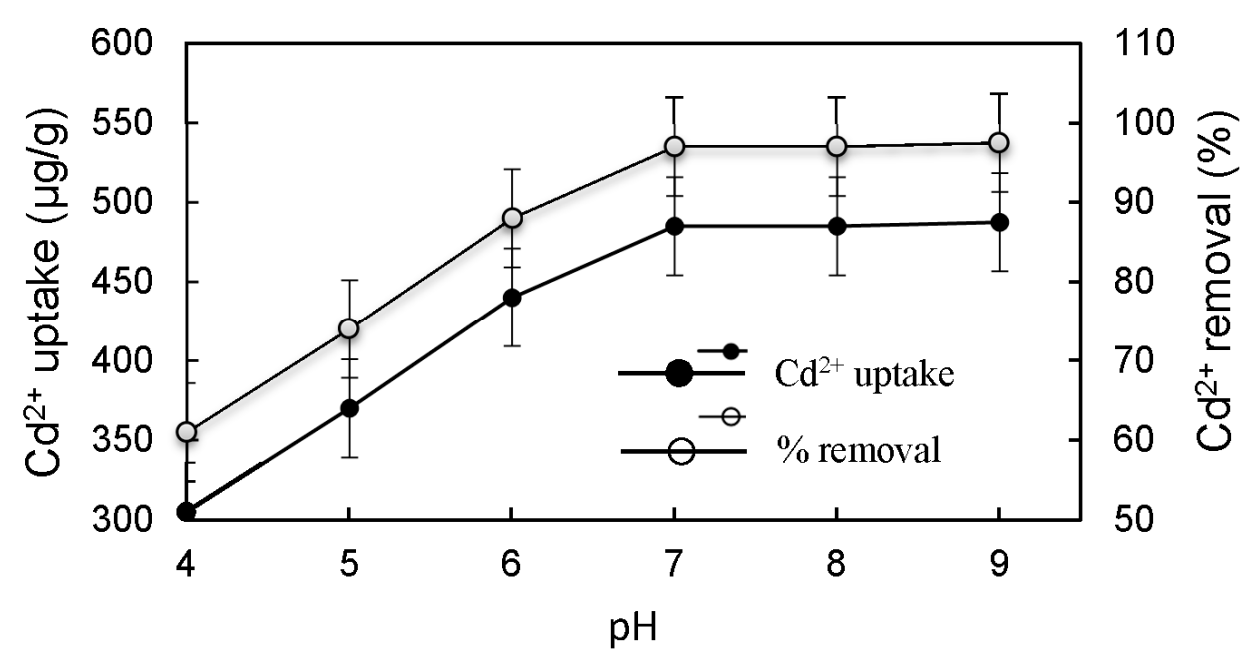

Figure 7. Effect of equilibrium solution $\mathrm{pH}$ on $\mathrm{Cd}^{2+}$ uptake and removal.

The kinetics of $\mathrm{Cd}^{2+}$ removal by CMS of $2 \%$ modification is shown in Figure 8. Equilibrium was able to be reached in $90 \mathrm{~min}$. The data were fitted to several kinetic models, and the pseudo second-order model fitted the data best $\left(\mathrm{r}^{2}=0.98\right)$. This has the formula:

$$
q_{t}=\frac{k q_{e}^{2} t}{1+k q_{e} t}
$$

where $k(\mathrm{~g} / \mu \mathrm{g}-\mathrm{min})$ is the rate constant of adsorption, $q_{e}(\mu \mathrm{g} / \mathrm{g})$ the amount of $\mathrm{Cd}^{2+}$ adsorbed at equilibrium, and $q_{t}(\mu \mathrm{g} / \mathrm{g})$ is the amount of $\mathrm{Cd}^{2+}$ adsorbed on the surface of the adsorbent at any time, $t$. The fitted values are $q_{e}=625 \mu \mathrm{g} / \mathrm{g}, k=4.6 \times 10^{-5} \mathrm{~g} / \mu \mathrm{g}$-min, and the rate constant is $17.8 \mu \mathrm{g} / \mathrm{g}$-min.

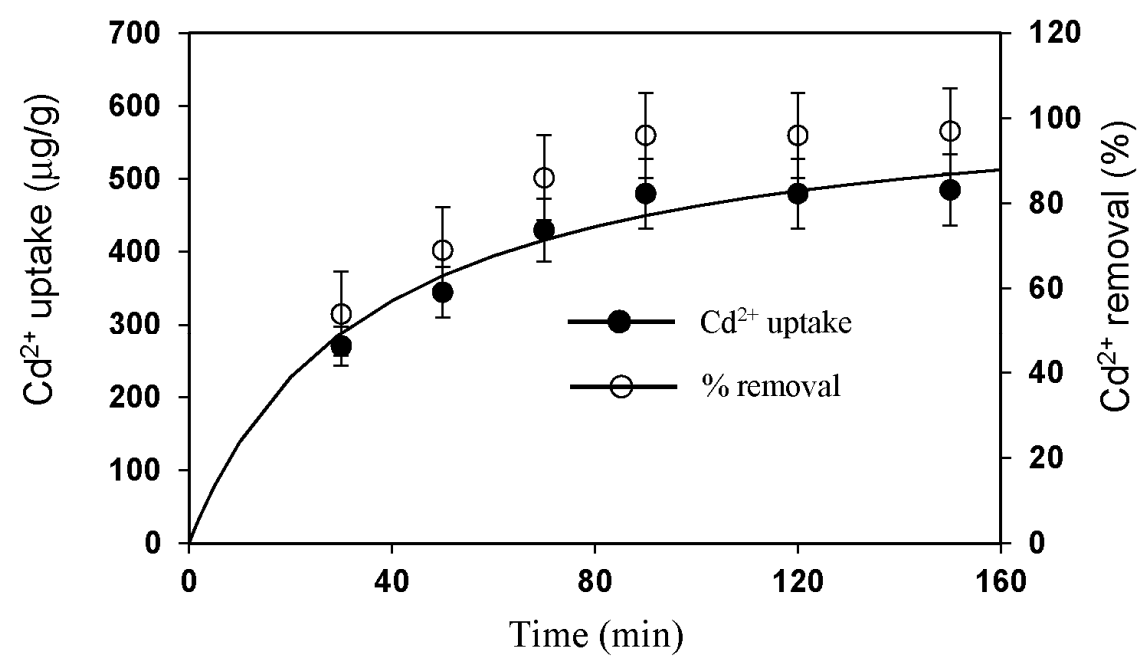

Figure 8. Kinetics of $\mathrm{Cd}^{2+}$ uptake and removal. 
For the best application, the dosage of CMS was also evaluated. When the dosage of CMS was increased from 0.1 to $0.2 \mathrm{~g}$, the cadmium removal quickly increased from $82.1 \%$ to $98.1 \%$ (Figure 9). The equilibrium $\mathrm{Cd}^{2+}$ was less than $2 \mu \mathrm{g} / \mathrm{L}$, which meets the standard $\mathrm{Cd}^{2+}$ emission of $10 \mu \mathrm{g} / \mathrm{L}$ prescribed in the Standards for Irrigation Water Quality (GB5084-2005) and the MCL and MCLG of $5 \mu \mathrm{g} / \mathrm{L}$ for ground water and drinking water set by USEPA.

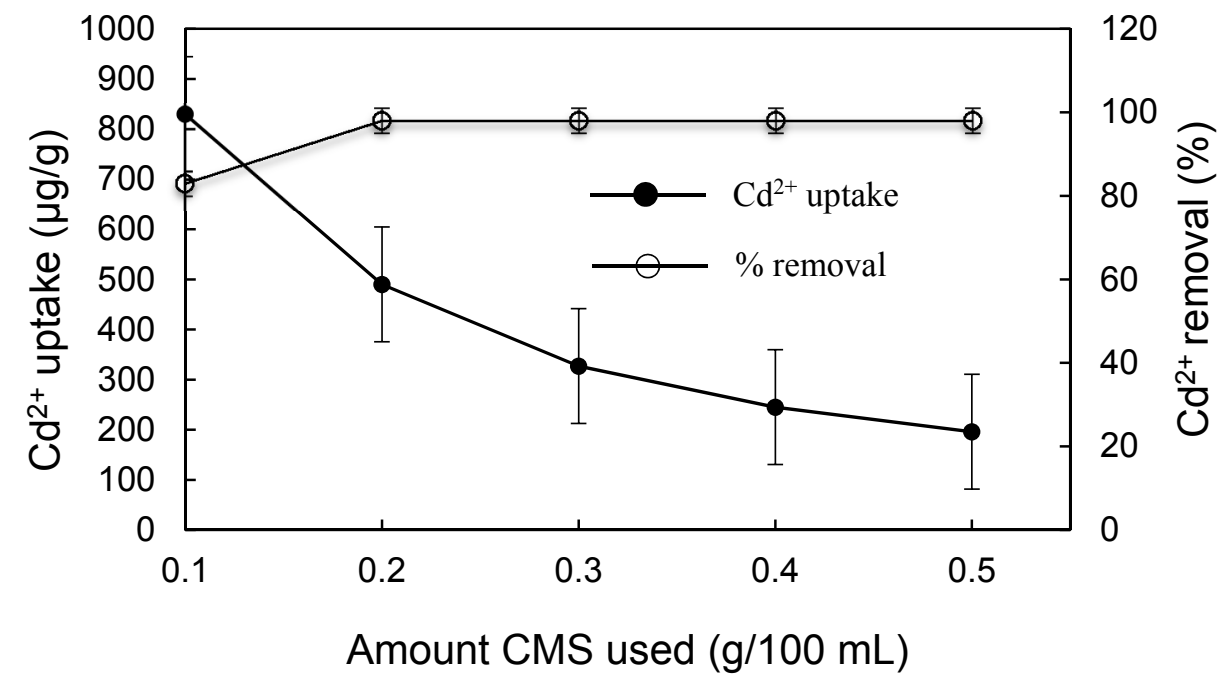

Figure 9. Effect of dosage of CMS on $\mathrm{Cd}^{2+}$ uptake and removal.

The isotherm of $\mathrm{Cd}^{2+}$ uptake was fitted to both the Langmuir and Freundlich models, and the Langmuir model resulted in a much better fit for the experimental data, with a $\mathrm{Cd}^{2+}$ uptake capacity of $1 \mathrm{mg} / \mathrm{g}$ (Figure 10 and Table 1). The Langmuir sorption isotherm has the form:

$$
C_{S}=\frac{K_{L} S_{m} C_{L}}{1+K_{L} C_{L}}
$$

where $C_{S}$ is the amount of $\mathrm{Cd}^{2+}$ adsorbed at equilibrium $(\mu \mathrm{g} / \mathrm{g}), S_{m}$ the apparent sorption capacity $(\mu \mathrm{g} / \mathrm{g}), C_{L}$ the equilibrium $\mathrm{Cd}^{2+}$ concentration $(\mu \mathrm{g} / \mathrm{L})$, and $K_{L}$ the Langmuir coefficient $(\mathrm{L} / \mu \mathrm{g})$. The Freundlich isotherm has the formula:

$$
C_{S}=K_{F} C_{L}^{n}
$$

where $K_{F}, n$, and Freundlich constants reflect the adsorption capacity and intensity, respectively. The agreement with the Langmuir model suggested the monolayer adsorption of $\mathrm{Cd}^{2+}$ on CMS surfaces, confirming the effectiveness of chitosan modification.

The $\mathrm{Cd}^{2+}$ uptake and removal by CMS was compared to that by MS without chitosan modification. A reduction of almost 80 times in equilibrium $\mathrm{Cd}^{2+}$ concentration, or a 10-fold increase in $\mathrm{Cd}^{2+}$ uptake was achieved by CMS in comparison to MS alone (Table 2).

Preliminary studies showed that the $\mathrm{Cd}^{2+}$ uptake and removal was endothermic with the $\Delta \mathrm{G}$, $\Delta \mathrm{H}$, and $\Delta \mathrm{S}$ values of $7.4 \mathrm{~kJ} / \mathrm{mol}, 50.6 \mathrm{~kJ} / \mathrm{mol}$, and $0.2 \mathrm{~kJ} /(\mathrm{mol} \cdot \mathrm{K})$, respectively.

The chitosan molecules have large amounts of amino and hydroxyl groups. These functional groups could form complexation with divalent metal cations. Previous results showed that one $\mathrm{Cu}$ (II) cation complexed with two amino and groups of chitosan [22]. The agreement of the pseudo-second order kinetic data also pointed to chemisorption $[18,19]$. 


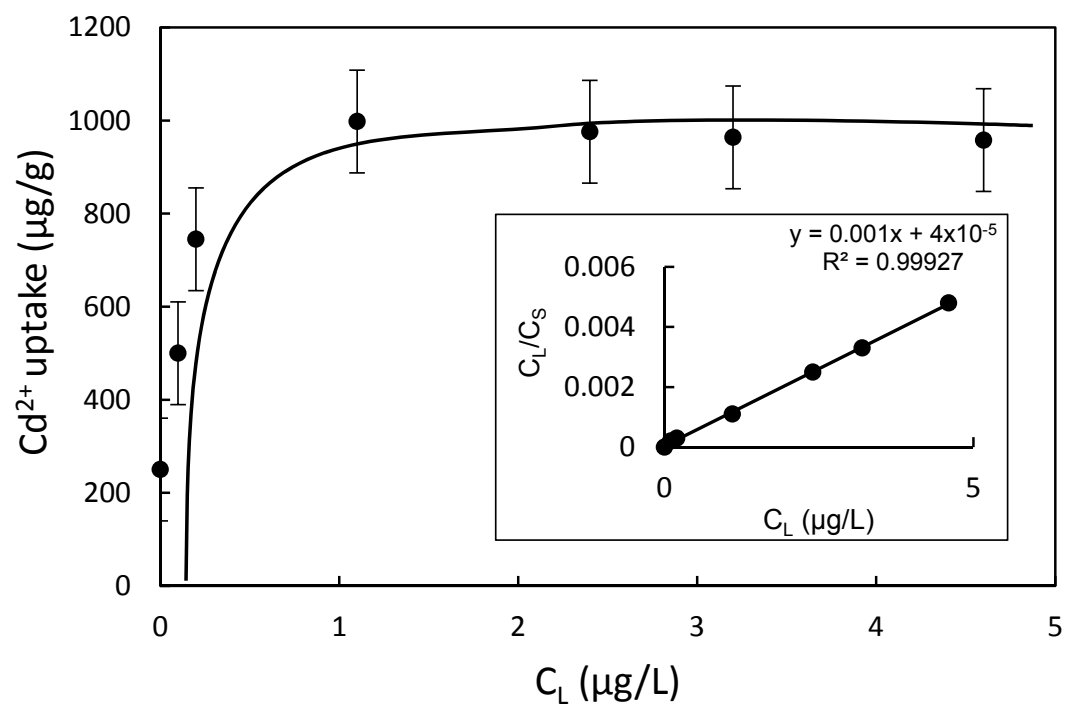

Figure 10. Uptake of $\mathrm{Cd}^{2+}$ on CMS. The inset is the linear Langmuir fit to the observed data.

Table 1. Langmuir and Freundlich parameters for $\mathrm{Cd}^{2+}$ uptake on CMS.

\begin{tabular}{cccccc}
\hline & Langmuir Constant & \multicolumn{3}{c}{ Freundlich Constant } \\
\hline$S_{m}(\mu \mathrm{g} / \mathrm{g})$ & $K_{L}(\mathrm{~L} / \mu \mathrm{g})$ & $\mathbf{R}^{\mathbf{2}}$ & logk & $\mathbf{1} / \boldsymbol{n}$ & $\mathbf{R}^{\mathbf{2}}$ \\
\hline 1000 & 25 & 0.9993 & 2.70 & 0.534 & 0.47 \\
\hline
\end{tabular}

Table 2. Comparison of $\mathrm{Cd}^{2+}$ removal by MS and CMS.

\begin{tabular}{cccc}
\hline Sample & $\mathrm{C}_{\mathrm{L}}(\mu \mathrm{g} / \mathrm{L})$ & Removal $(\%)$ & $\mathrm{C}_{\mathrm{S}}(\mu \mathrm{g} / \mathrm{g})$ \\
\hline MS & 82.1 & 17.9 & 89.5 \\
CMS & 1.1 & 98.7 & 985 \\
\hline
\end{tabular}

\section{Conclusions}

1. The optimal condition for the preparation of CMS was mixing $2 \%$ chitosan solution with MS for $2 \mathrm{~h}$.

2. SEM and XRD results showed no change in crystal morphology of MS after modification. However, the increase in C and N contents in EDS spectra, the increase in $2 \%$ of mass loss in TGA analysis, and the presence of 2850 and $2920 \mathrm{~cm}^{-1}$ bands in FTIR analyses confirmed chitosan uptake on MS after modification.

3. The static single factor experiment results showed that under the condition of room temperature, $\mathrm{pH}$ of 7, vibration adsorption time of $90 \mathrm{~min}$, and adsorbent dosage of $2 \mathrm{~g} / \mathrm{L}$, the $\mathrm{Cd}^{2+}$ removal from simulated wastewater with an initial concentration of $100 \mu \mathrm{g} / \mathrm{L}$ was over $96 \%$ when using CMS as the adsorbent, which meets the standard $\mathrm{Cd}^{2+}$ discharge prescribed in the Standards for Irrigation Water Quality (GB5084-2005) and the MCL and MCLG for groundwater and drinking water standards set by USEPA.

4. The adsorption process of lower concentration of $\mathrm{Cd}^{2+}$ in water by CMS fitted with the Langmuir adsorption isotherm model well, with a saturated adsorption capacity of $1 \mathrm{mg} / \mathrm{g}$.

Acknowledgments: This research is supported by the Henan Province Program for Science and Technology Research (172102210055 and 162102210077); the "Twelfth Five Year Plan" 863 project; Key Technology in Remediation of Sewage Irrigation Farmland and Degraded Soil (2012AA101404); Key Scientific Research Project in Henan Province (18B570004 and 15A610008); College Students' Innovative Experimental Program (2016082); and North China University of Water Resources and Electric Power of Engineering Research Fund Project (201610009). 
Author Contributions: All authors have contributed in various degrees to the analytical methods used, to the research concept, to the experiment design, to the acquisition of data, or analysis and interpretation of data, to draft the manuscript or to revise it critically for important intellectual content.

Conflicts of Interest: The authors declare no conflict of interest.

\section{References}

1. Wang, H.D.; Fang, F.M.; Xie, H.F. Research situation and outlook on heavy metal pollution in water environment of China. Guangdong Trace Elem. Sci. 2010, 17, 14-18.

2. Zhan, J.; Wei, S.H. Methods of inhibiting cadmium toxicity and its mechanism: A review. Asian J. Ecotoxicol. 2012, 4, 354-359.

3. Yue, X.Y.; Yi, J. Cadmium poisoning and preventing. Sichuan Anim. Vet. Sci. 2000, 7, $28-29$.

4. Du, L.N.; Yu, R.Z.; Wang, H.Y.; Lu, Y.; Liu, Z.T. Pollution and toxicity of cadmium: A review of recent studies. J. Environ. Health 2013, 2, 167-174.

5. USEPA. National Primary Drinking Water Regulations. Available online: https://www.epa.gov/groundwater-and-drinking-water/national-primary-drinking-water-regulations (accessed on 15 September 2017).

6. Friberg, L.; Nordberg, G.F.; Vouk, V.B. Handbook on the Toxicology of Metals, 3rd ed.; Elsevier: Amsterdam, The Netherlands, 2007; pp. 130-184.

7. World Health Organization; United Nations Environment Programme; Global Environment Monitoring System. Global Fresh Water Quality; Published on behalf of the World Health Organization/United Nations Environment Programme; Blackwell Reference: Oxford, UK, 1989.

8. Mustafa, H.T. Cadmium and zinc concentrations in the potable water of the eastern provinces of Saudi Arabia. Bull. Environ. Contam. Toxicol. 1988, 40, 462-467. [CrossRef] [PubMed]

9. Dai, S.M.; Lv, X.W. Advances on cadmium pollution water treatment technology. Saf. Environ. Eng. 2006, 13, 63-65.

10. Hu, K.W.; Jia, D.Y.; Zha, C.M. Effect of zeolite on competitive sdsorption of heavy metals ions. Soil Fertil. Sci. China 2008, 3, 66-69.

11. He, H.P.; Guo, J.G.; Zhu, J.X. An experimental study of adsorption capacity of montmorillonite, kaolinite and illite for heavy metals. Acta Petrol. Mineral. 2001, 20, 573-578.

12. Zou, Z.H.; He, S.F.; Han, C.Y. Progress of heavy metals liquid waste processing technique. Technol. Water Treat. 2010, 6, 19-20.

13. Sun, X. Zeolite NaA and NaX Synthesis from Fly Ash and Their Adsorption of Heavy Metal Ions in Waste Water; Nan Jing University of Science and Technology: Nanjing, China, 2007.

14. Van Mao, R.L.; Xiao, S.; Ramsaran, A.; Yao, J. Selective removal of silicon from zeolite frameworks using sodium carbonate. J. Mater. Chem. 1994, 4, 605-610. [CrossRef]

15. Xu, R.R.; Pang, W.Q.; Yu, J.H. Chemistry-Zeolite and Oorous Materials; Science Press: Beijing, China, 2004; pp. 356-409.

16. Qin, C.; Li, H.; Xiao, Q.; Liu, Y.; Zhu, J.; Du, Y. Water-solubility of chitosan and its antimicrobial activity. Carbohydr. Polym. 2006, 63, 367-374. [CrossRef]

17. Hasan, S.; Ghosh, T.; Viswanath, D. Dispersion of chitosan on perlite for enhancement of copper adsorption capacity. J. Hazard. Mater. 2008, 152, 826-837. [CrossRef] [PubMed]

18. Ngah, W.S.W.; Teong, L.C.; Toh, R.H.; Hanafiah, M.A.K.M. Utilization of chitosan-zeolite composite in the removal of $\mathrm{Cu}(\mathrm{II})$ from aqueous solution: Adsorption, desorption and fixed bed column studies. Chem. Eng. J. 2012, 209, 46-53. [CrossRef]

19. Ngah, W.S.W.; Teong, L.C.; Toh, R.H.; Hanafiah, M.A.K.M. Comparative study on adsorption and desorption of $\mathrm{Cu}$ (II) ions by three types of chitosan-zeolite composites. Chem. Eng. J. 2013, 223, 231-238. [CrossRef]

20. Xie, J.; Li, C.; Chi, L.; Wu, D. Chitosan modified zeolite as a versatile adsorbent for the removal of different pollutants from water. Fuel 2013, 103, 480-485. [CrossRef]

21. Lu, C.; Yu, S.; Yao, T.; Zeng, C.; Wang, C.; Zhang, L. Zeolite X/chitosan hybrid microspheres and their adsorption properties for $\mathrm{Cu}$ (II) ions in aqueous solutions. J. Porous Mater. 2015, 22, 1255-1263. [CrossRef]

22. Djelad, A.; Morsli, A.; Robitzer, M.; Bengueddach, A.; Di Renzo, F.; Quignard, F. Sorption of Cu (II) ions on chitosan-zeolite X composites: Impact of gelling and drying conditions. Molecules 2016, 21, 109. [CrossRef] [PubMed] 
23. Kołodyńska, D.; Hałas, P.; Franus, M.; Hubicki, Z. Zeolite properties improvement by chitosan modification-Sorption studies. J. Ind. Eng. Chem. 2017, 52, 187-196. [CrossRef]

24. Hałas, P.; Kołodyńska, D.; Płaza, A.; Gęca, M.; Hubicki, Z. Modified fly ash and zeolites as an effective adsorbent for metal ions from aqueous solution. Adsorpt. Sci. Technol. 2017, 35, 519-533. [CrossRef]

25. Płaza, A.; Kołodyńska, D.; Hałas, P.; Gęca, M.; Franus, M.; Hubicki, Z. The zeolite modified by chitosan as an adsorbent for environmental applications. Adsorpt. Sci. Technol. 2017. [CrossRef]

26. Hamza, M.F.; Aly, M.M.; Abdel-Rahman, A.A.H.; Ramadan, S.; Raslan, H.; Wang, S.; Vincent, T.; Guibal, E. Functionalization of magnetic chitosan particles for the sorption of U (VI), Cu (II) and Zn (II) - Hydrazide derivative of glycine-grafted chitosan. Materials 2017, 10, 539. [CrossRef] [PubMed]

2017 by the authors. Licensee MDPI, Basel, Switzerland. This article is an open access article distributed under the terms and conditions of the Creative Commons Attribution (CC BY) license (http://creativecommons.org/licenses/by/4.0/). 